\title{
More Than Flow: Revisiting the Theory of Four Channels of Flow
}

\author{
Ching-I Teng and Han-Chung Huang \\ Graduate Institute of Business and Management, Chang Gung University, Taoyuan 333, Taiwan \\ Correspondence should be addressed to Ching-I Teng, chingit@mail.cgu.edu.tw
}

Received 27 December 2011; Revised 16 April 2012; Accepted 17 April 2012

Academic Editor: Daniel Thalmann

Copyright ( 12012 C.-I. Teng and H.-C. Huang. This is an open access article distributed under the Creative Commons Attribution License, which permits unrestricted use, distribution, and reproduction in any medium, provided the original work is properly cited.

\begin{abstract}
Flow (FCF) theory has received considerable attention in recent decades. In addition to flow, FCF theory proposed three influential factors, that is, boredom, frustration, and apathy. While these factors have received relatively less attention than flow, Internet applications have grown exponentially, warranting a closer reexamination of the applicability of the FCF theory. Thus, this study tested the theory that high/low levels of skill and challenge lead to four channels of flow. The study sample included 253 online gamers who provided valid responses to an online survey. Analytical results support the FCF theory, although a few exceptions were noted. First, skill was insignificantly related to apathy, possibly because low-skill users can realize significant achievements to compensate for their apathy. Moreover, in contrast with the FCF theory, challenge was positively related to boredom, revealing that gamers become bored with difficult yet repetitive challenges. Two important findings suggest new directions for FCF theory.
\end{abstract}

\section{Introduction}

The application of flow theory to multiple Internet contexts [1-4] reflects its prominent role in information systems research. In their pioneering work, Csikszentmihalyi [5] proposed the four channels of flow (FCF) theory, that is, flow, boredom, frustration, and apathy, and also posited that skill and challenge are major components in each of those channels.

Flow refers to the involvement of individuals in activities with full concentration and their subsequent enjoyment [6], whereas those individuals experience flow through high degree of skills to control challenges [1]. Such highly enjoyable experiences cause individuals to become more involved in related activities, allowing them to perceive enjoyment, control, and intrinsic enjoyment [2]. Therefore, high levels of skills and challenges create the perception of flow.

Boredom occurs when a person experiences monotony, insipidity, and a lack of stimuli [7]. Individuals may feel disinterested and lacking in concentration for an activity, resulting in unpleasant emotions [8]. Moreover, boredom creates a passive perception towards stimuli [9]. Enhanced skills likely shift individuals from involvement to boredom [8]. Therefore, highly skilled individuals are more likely to familiarize themselves with the stimuli related to an activity, subsequently giving rise to boredom.

Frustration refers to the inability of individuals to solve problems or satisfy demand involving discontent or insecure perceptions [7]. Although frustration may produce negative emotions under obstructions from individuals, circumstances, and things, Goodstein and Lanyon [10] suggested that frustration may motivate individuals to achieve certain goals. Therefore, frustration is occasionally regarded as essential to enhancing an overall experience [11].

Apathy refers to individual carelessness towards certain circumstances and an unwillingness to remain alert [7]. Apathy originates from obtaining a lower degree of achievement or having no interest in certain activities. Emotive feelings of unconcern and unwillingness lead to a failure to concentrate on certain activities. Therefore, individuals lacking sufficient capabilities cannot achieve success in activities, discouraging them from further interest or participation in related activities, and ultimately resulting in the feeling of apathy.

Dimensions of skill and challenge can determine the above four channels [5]. High skill and high challenge create flow; high skill and low challenge create boredom; low skill and high challenge create frustration; low skill and low challenge create apathy. 
Of the four channels, flow has received the most attention in many disciplines [12-14], with notable examples found in studies on happiness [6], telepresence, time distortion [15], interactivity, involvement [16], and exploratory behavior [17], thus reflecting its widespread applicability.

However, boredom, frustration, and apathy have received lesser attention than flow, which represents a considerable research gap. The inability to thoroughly understand these factors makes it impossible for information system designers to assess how user skill and challenge profoundly impact their systems. Moreover, the exponential growth and acceleration of Internet applications warrants a closer examination of the FCF theory. Despite recent studies on boredom [8] and frustration [11], the FCF theory has not been studied from a structural perspective, that is, using structural equation modeling to examine the all model components simultaneously, thus reflecting another research gap.

Therefore, this study investigates whether skill and challenge create four channels, as posited by FCF theory. This study significantly contributes to current literature in three ways. First, the FCF theory posits that skill and challenge determine whether an individual experiences flow, frustration, boredom, and apathy $[5,6]$. While reexamining the four channels, this study explores how skill and challenge nurture those channels in online games.

Second, despite conjecturing that skill and challenge can predict flow, Skadberg and Kimmel [14] offered no supporting evidence, possibly owing to their lack of challenges requiring high skill levels. Given the ambiguous findings of their study, FCF theory warrants a closer examination in other information system contexts. Therefore, this study examines the role of FCF theory in online gaming, which involves difficult challenges and is also an important information medium.

Third, an exhaustive review by Hoffman and Novak [18] established the usefulness of flow in information systems research, revealing that the components of FCF theory are worthwhile research directions. Therefore, exactly how skill and challenge formulate the other three channels of boredom, frustration, and apathy must be examined. By addressing this theoretical gap, this study significantly contributes to future studies on flow and the other three novel and influential factors.

\section{Theoretical Background}

2.1. Flow. Flow refers to the highly enjoyable experience of intense concentration on a specific activity [6]. Individuals of any age, race, and culture can experience flow [6]. Although immersion is viewed as the prestate of flow due to the disorientation, flow shows a full commitment [19]. The degree of immersion is significantly affected by the results and significance of individual actions in a particular environment and the influence of those actions on the games [19]. Having received considerable theoretical and empirical attention, flow has been applied in many fields. According to previous studies, flow is essential to favorable user responses $[2,4]$, reflecting its relevance to information systems research. Notably, although having received considerable attention, flow has seldom been examined with respect to the other three channels in the FCF theory, that is, boredom, frustration, and apathy.

Flow is also a notable function of the internal brain structure in humans. According to a previous study, both cognitive science and neuroscience are applicable in examining brain functions and analyzing the state of flow. The frontal lobe and medial temporal lobe structures containing higher cognitions developed with flexibility in cognition are associated with an explicit system [20]. However, such an implicit system also involves knowledge and skills acquired from basal ganglia, thereby achieving a high efficiency in processing information and making decisions. Based on the dilemma between flexibility and efficiency, the state of flow represents high skills that have been practiced for a considerable time in an implicit system without any interferences from an explicit one [20].

Although individuals may or may not remain pleased with a particular task, their emotional state can be monitored by psychological symptoms. The central nervous system and the peripheral nervous system, for example, blood pressure, respiration, and temperature, exhibit physiological signals, which are genuine and emotional processes that can be partially interpreted [7]. Since different levels of a challenge cause various emotional reactions, individuals tend to switch from active involvement to boredom when their skills are enhanced [8]. Conversely, when individuals can not further improve in terms of quality of skills, their emotional state may shift from active involvement to anxiety [8].

Antecedents of flow include a well-designed learner interface, positive user-computer interaction [21], playfulness, telepresence, control [22], skill, and challenge [14]. Of those antecedents, skill and challenge are the most widely discussed. Skill refers to the ability to resolve difficult problems [6] while challenge refers to a complex task requiring completion [1]. Highly skilled users faced with challenging problems are likely to experience flow [23], explaining why skill and challenge should be considered major antecedents of flow.

Despite the applicability of the flow construct in many activities [2-4], online games have received considerable attention $[2,4,24]$. For instance, flow experience extended when incorporating increased difficulty in games in terms of development of necessary metal states, thus providing a regular state of balance between increased challenges and skills [25]. Additionally, in comparison with playing online game via computer- and human-controlled opponents, that study also demonstrated that playing against competitors controlled by a real human creates more presence, flow, and enjoyment [25]. Moreover, skill and challenge are often discussed in terms of flow in online gaming [4], thus making online games highly appropriate for examining flow theories.

2.2. Flow Theories. Csikszentmihalyi [5] pioneered the theory of the three channels of flow, in which flow only appears after reaching a balanced state between skill and challenge. When individual skills fail to adequately respond, individuals experience anxiety; in contrast, when their skills exceed those required in specific challenges, individuals tend to search 
for more challenging activities [26]. In a flow experience, individuals experience control and intrinsic pleasures [2]. A previous study characterized the flow construct according to eight elements, that is a clear goal, feedback, challenges that match skills, concentration and focus, control, loss of consciousness, transformation of time, and a self-reinforcing activity [6].

Hoffman, Novak, and their colleagues $[1,17,27]$ developed a conceptual model based on flow. Based on that model, three aspects were investigated. First, causes of flow for Internet users included both motivations, skills from the individual and vividness, and challenges from online activities. Second, the online experience made the individual more involved and focused, easily leading to flow. Third, the flow experience related to online activities triggered a positive attitude and thoughts for the individual, creating an impetus to increase learning ability. Additionally, the importance of variables changes over time. The skill levels may improve owing to the increased time spent on Internet sites. Conversely, challenge, telepresence, and the desire to explore online activities may diminish.

Several theoretical models or frameworks have been developed for flow. Agarwal and Karahanna [28] also proposed cognitive absorption in comparison with flow. Cognitive absorption refers to operating computer programs, and is considered as belonging to multidimensional perception constructs, including temporal dissociation, focused immersion, heightened enjoyment, control, and curiosity. Personal traits and cognitive absorption are also related. Both playfulness and personal innovativeness profoundly impact cognitive absorption. Additionally, technology use such as perceived usefulness and perceived ease of use may constitute major antecedents of cognitive absorption. Moreover, Richard and Chandra [16] investigated Web navigation behavior empirically, indicating that flow arises from enjoyment, time distortion, and telepresence is a highly effective means of elucidating the web navigation behavior of visitors. Such studies confirm that flow plays a major role in computer research.

The four channels of flow theory (the FCF theory) [5], that is, the leading theory on flow creation, posits that high/low skill levels and challenges create four channels: flow, boredom, frustration, and apathy. Of those, flow has received the most attention, likely owing to that flow triggers positive user responses. Flow is generally accompanied by enhanced happiness $[6,29]$, thus highly motivating users to engage in repetitive activities [30].

The FCF theory should be examined by evaluating flow and the other three factors at different skill and challenge levels, as posited by the FCF theory. Skill refers to the ability to engage in current activities [17]. Highly skilled individuals can overcome difficulties, subsequently creating intrinsic enjoyment. A high skill level may thus nurture flow. However, highly skilled individuals may consider themselves as experts, thus diminishing their interest and concentration level and increasing their feelings of boredom. Conversely, low-skilled individuals likely experience difficulties that prevent them from achieving their goals, subsequently increasing their feelings of frustration. Finally, given their lack of skills to achieve goals, such individuals may become discouraged and withdraw from further activity. Restated, they become apathetic. Therefore, the FCF theory posits the following.

(H1a) Skill is positively related to flow.

(H1b) Skill is positively related to boredom.

(H1c) Skill is negatively related to frustration.

(H1d) Skill is negatively related to apathy.

Challenge refers to competition and obstacles encountered in activities [31]. Challenge may inspire individuals to win competitions and overcome obstacles, fostering a sense of achievement. However, too much challenge causes frustration while insufficient challenge leads to boredom [8]. Frustration occurs when individuals fail to progress further due to the inability to operate or perform well [11]. To do so, individuals must concentrate to fully realize their capabilities. Increased concentration is a major element of flow [6]. Thus, a high challenge is likely to create a flow experience. Challenges inspire individuals to win competitions and overcome obstacles, likely motivating them to seek new ways of winning, ultimately reducing their boredom. Conversely, challenges considered too difficult to overcome would prevent users from winning, ultimately increasing their frustration. Individuals may also be attracted to competitive challenges, which diminish feelings of apathy. Therefore, the FCF theory posits the following.

(H2a) Challenge is positively related to flow.

(H2b) Challenge is negatively related to boredom.

(H2c) Challenge is positively related to frustration.

(H2d) Challenge is negatively related to apathy.

The above eight hypotheses represent the foundation of the FCF theory [5] and were not initially developed in this study. This study reexamines the FCF theory owing to exponential growth and accelerated changes in Internet applications. Thus rather than proposing a new hypothesis, this study examines all eight hypotheses from the perspective of FCF theory. Figure 1 illustrates the research framework of this study.

\section{Method}

3.1. Sample and Data Collection. Testing the validity of the FCF theory requires a research context involving high/low user skills and challenges. Online game complexity may require collaborating in teams, solving problems, and exploring the game worlds. Online games can also be rather simple by only requiring minimum mental efforts. Online games thus involve high/low levels of challenges. Moreover, online gamers may range from novices to experts, creating high/low levels of skills. Thus, online games meet the criterion of this study to test the validity of the FCF theory. Moreover, online games have emerged as influential information systems. For instance, recent studies [32, 33] have established the relevance of online games in current research. 


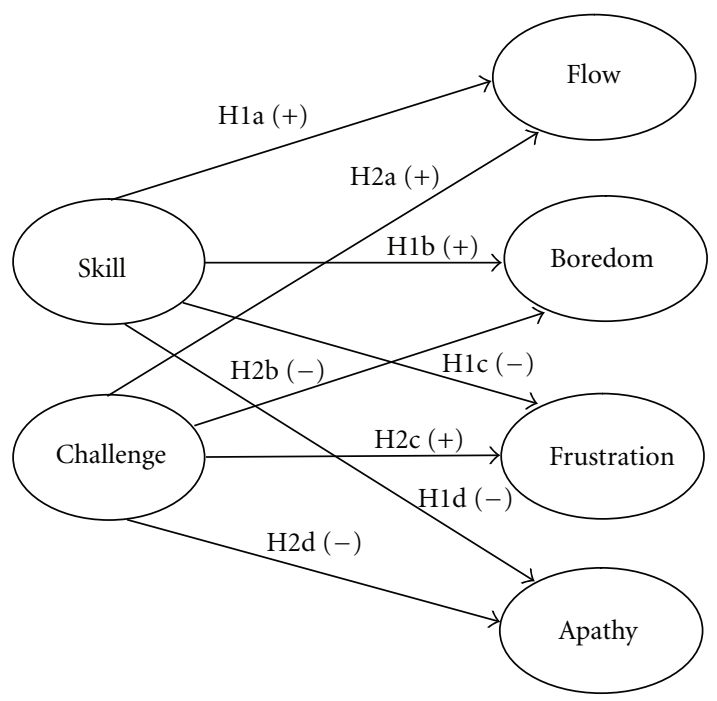

FIgURE 1: Theoretical framework.

To reduce the likelihood of a sampling bias owing to few sources of respondents, this study solicited respondents from more than twenty forums and electronic bulletins associated with online games. Data were collected using a web form. The web form cover pages stated that this study focused on gaming experiences. Respondents whom consented to participate were encouraged to enter a lottery in which 50 winners received a \$US 16 gift certificate.

Participants were instructed to provide the name of their favorite games, their occupations, race, or other avatar identifiers. Among their favorite online games included World of Warcraft, Mabinogi, Lineage, and Crazyracing. Instructing respondents to rate their favorite games may reduce the likelihood of a memory bias, an approach which has been used in recent literature, for example, [32]. Such information was reviewed to verify the validity of the response, that is, whether respondent had online game playing experiences. When such information was determined to be meaningless or incorrect, the related response was considered invalid. Moreover, the internet protocol (IP) addresses and email addresses of the respondents were recorded and compared to eliminate respondents with multiple responses.

Of the 309 web forms submitted, 253 were valid, yielding an effective response ratio of $81.9 \%$. Of the 253 respondents submitting valid forms, $63.9 \%$ were male; $46.2 \%$ were younger than 22 years old; $96.4 \%$ had attended colleges or universities (including graduate or above); $44.7 \%$ had a monthly disposable income exceeding \$US 100. Hsu and $\mathrm{Lu}$ [34] observed that most online gamers had 1-3 years of experience playing online games. The respondents in this study had an average of 15.2 months experience playing online games, which corresponded to the findings of Hsu and $\mathrm{Lu}$ [34]. Over the past six months, the average time spent on the online game was 13.8 hours weekly.

In comparison with the study of Williams et al. [35], which surveyed players of Everquest 2, this study provided the following results of interest. Regarding the mean age of players, Williams et al. [35] indicated that the age of 31.6 years old matched the mean age of general US population (35.5 years old). Such findings contradicted the stereotype of young gamers. However, our findings somewhat differ from those of Williams et al. [35]. Most of our respondents ranged from 20 to 25 years old, reflecting that the local gamers are youth. Moreover, $80 \%$ of the respondents of Williams et al. [35] were male. Results of this study are consistent with those of previous studies in which $64 \%$ of the respondents were male. With respect to income and education distributions, Everquest 2 players (as in [35]) came from more wealthy families than average ones. Conversely, respondents in this study had a low income since most of the adolescents had a lower than average income. In sum, characteristics of respondents in this study were largely young adults with low disposable incomes.

3.2. Measurement. Most measurement instruments came from previous studies. Items measuring skill, challenge, and flow were adapted from the scales of Novak et al. [17]. Pertinent literature lacks a consensus on how to measure flow [18]. Therefore, in this study, the scale of Novak et al. [17] was used, which was also used in an online gaming study of $\mathrm{Hsu}$ and Lu [2]. This study followed the study of Hsu and Lu [2] in explaining the flow concept to the participants prior to they providing responses to the study items regarding flow. The present study explained flow to the participants using two sentences: "Flow is the individual state of concentration in which time is perceived as still" and "Flow makes an individual experience intrinsic enjoyment." This approach of explaining flow and then directly measuring flow has been widely adopted in the literature [2, 17]. Moreover, participants in the present study did not raise any questions regarding the meaning of flow. Thus the measurement of flow in this study is adequate and understandable to participants. Items measuring boredom, frustration, and apathy originated from the scales of Kammann and Flett [36] and Kozma and Stones [37]. The measurement tools adopted Likert scales. All items involved a response option ranging from 1 (very disagreeable) to 5 (very agreeable), and were slightly modified to comply with the research context. All respondents were instructed to evaluate their favorite online games. Thus, "the game" in measurement items referred to the game favored by the individual respondent rather than to a single game specified for all respondents. Notably, rating favorite games may somewhat increase the scores of some constructs, but may not change the relations between constructs. Since hypotheses state relations between constructs, rating favorite games may not bring marked biases. Moreover, rating favorite games increases the number of games included in this study, subsequently enhancing the generality of the study findings. Such an approach has also been adopted previously [38].

This study performed a confirmatory factor analysis to directly assess measurement reliability and validity. Confirmatory factor analysis is extensively adopted to assessing the reliability and validity of psychological assessments $[39,40]$. All measures had a Cronbach $\alpha>$.7, a composite reliability $(\mathrm{CR})>.6$, and an average variance extracted $(\mathrm{AVE})>.5$, which satisfied the reliability criteria of Bagozzi and Yi [41]. 
TABLE 1: Summary of confirmatory factor analysis.

\begin{tabular}{|c|c|c|c|c|c|c|}
\hline & $\mu$ & SD & $\lambda$ & $\alpha$ & CR & AVE \\
\hline Skill & & & & .87 & .91 & .72 \\
\hline I am extremely skilled at playing the game. & 3.34 & 0.81 & 0.83 & & & \\
\hline I have rich knowledge regarding the game. & 3.68 & 0.82 & 0.86 & & & \\
\hline Compared to most gamers, I am more familiar with the game. & 3.20 & 0.95 & 0.91 & & & \\
\hline My skill in playing the game is superior to using other software. & 3.31 & 0.92 & 0.78 & & & \\
\hline Challenge & & & & .87 & .90 & .76 \\
\hline Playing the game challenges me to perform to the best of my ability. & 2.93 & 0.98 & 0.90 & & & \\
\hline Playing the game challenges me. & 3.35 & 0.97 & 0.78 & & & \\
\hline I find that playing the game stretches my capabilities to my limits. & 2.80 & 1.00 & 0.93 & & & \\
\hline Flow & & & & .87 & .92 & .85 \\
\hline I have experienced flow when playing the game. & 3.00 & 1.15 & 0.85 & & & \\
\hline I frequently experience flow when playing the game. & 2.51 & 0.98 & 0.99 & & & \\
\hline Boredom & & & & .73 & .98 & .95 \\
\hline I feel much more skilled than other gamers when playing the game. & 3.09 & 0.86 & 0.98 & & & \\
\hline Tasks in the game are very easy for me to complete. & 3.11 & 0.85 & 0.66 & & & \\
\hline Frustration & & & & .84 & .90 & .75 \\
\hline I find the game too frustrating. & 2.33 & 0.81 & 0.71 & & & \\
\hline I find the game too complex. & 2.30 & 0.83 & 0.88 & & & \\
\hline I find the game too difficult. & 2.20 & 0.79 & 0.98 & & & \\
\hline Apathy & & & & .96 & .98 & .91 \\
\hline I find the game boring. & 2.20 & 0.86 & 0.95 & & & \\
\hline I find the game uninteresting. & 2.18 & 0.86 & 0.98 & & & \\
\hline I find the game dull. & 2.15 & 0.87 & 0.98 & & & \\
\hline I find the game unattractive. & 2.05 & 0.83 & 0.90 & & & \\
\hline
\end{tabular}

TABLE 2: Correlations between study constructs.

\begin{tabular}{lccccc}
\hline & 1 & 2 & 3 & 4 & 5 \\
\hline (1) Skill & - & & & & \\
(2) Challenge & $.52^{* *}$ & - & & & \\
(3) Flow & $.34^{* *}$ & $.26^{* *}$ & - & & \\
(4) Boredom & $.69^{* *}$ & $.40^{* *}$ & $.30^{* *}$ & - & \\
(5) Frustration & $-.12^{*}$ & $.15^{* *}$ & .07 & $-.17^{* *}$ & - \\
(6) Apathy & $-.22^{* *}$ & $-.29^{* *}$ & $-.18^{* *}$ & $-.15^{* *}$ & $.30^{* *}$ \\
\hline
\end{tabular}

Note: ${ }^{*} P<.05,{ }^{* *} P<.01$.

All indicator loadings exceeded .5 and had $t$ values $>2$, which satisfied the convergent validity criterion of Anderson and Gerbing [42]. Moreover, the maximum squared correlation between constructs was below the minimum AVE, which satisfied the discriminant validity criterion specified by Fornell and Larcker [43]. Table 1 summarizes the confirmatory factor analysis results.

The theoretical model fits acceptably with the data $\left(\chi^{2}=\right.$ 532.39, RMSEA $=.10, \mathrm{CFI}=.89, \mathrm{IFI}=.89, \mathrm{NFI}=.88$, SRMR $=.06)$. Browne and Cudeck [44] recommended RMSEA, CFI, and IFI as the proper indices for evaluating the model fit. In this study, RMSEA equaled .10, approaching the criterion of Browne and Cudeck [45], since validity of the RMSEA index was doubted [46]. CFI approached .10, which is suggested by Bagozzi [47]. IFI also approached .10, as recommended by Bollen [48]. Moreover, SRMR was below .07 , satisfying the criterion of Bagozzi [47].
Table 2 lists the correlations between the study constructs. Study constructs revealed moderate-to-low correlations, indicating the discriminant validity of the measures and minimal influence of common method variance (CMV). However, formal statistical testing may provide further evidence of the minimal influence of CMV. This study followed the suggestion of Podsakoff et al. [49] by using one construct CMV to explain the variance of all items. The model with CMV had a $\chi^{2}$ value of 3867.70 with a degree of freedom of 135 , subsequently creating the $\chi^{2}$ value difference of $3335.31(=3867.70-532.39)$ and the degree of freedom difference of $11(=135-124)$. The $\chi^{2}$ value difference (3335.3) exceeded the threshold value (19.68= $\left.\chi^{2}(d f=11, \alpha=.05)\right)$. Namely, the model without CMV significantly outperformed the model with $\mathrm{CMV}$, supporting the negligible influence of CMV.

\section{Results}

Table 3 presents the demographic data for the study respondents. Also, the section of sample and data collection processes summarizes the demographics. To avoid redundancy, this section does not repeat the same information.

While performing a further analysis of the sample, this study portrayed the identification and appearance of online gaming players; whereas the number of male players was nearly twice that of female players and their educational background consisted mainly of university level (accounting 
TABLe 3: Sample description.

\begin{tabular}{lccc}
\hline Demographics & Classifications & Number & Percentage (\%) \\
\hline \multirow{2}{*}{ Gender } & Male & 162 & 64.0 \\
& Female & 91 & 36.0 \\
\hline \multirow{3}{*}{ Education } & High school & 9 & 3.6 \\
& College or university & 213 & 84.2 \\
Monthly & Graduate or above & 31 & 12.2 \\
\multirow{2}{*}{ Disposable income } & Under \$100 & 140 & 55.3 \\
& \$101-\$300 & 92 & 36.4 \\
& \$30 and above & 21 & 8.3 \\
\hline
\end{tabular}

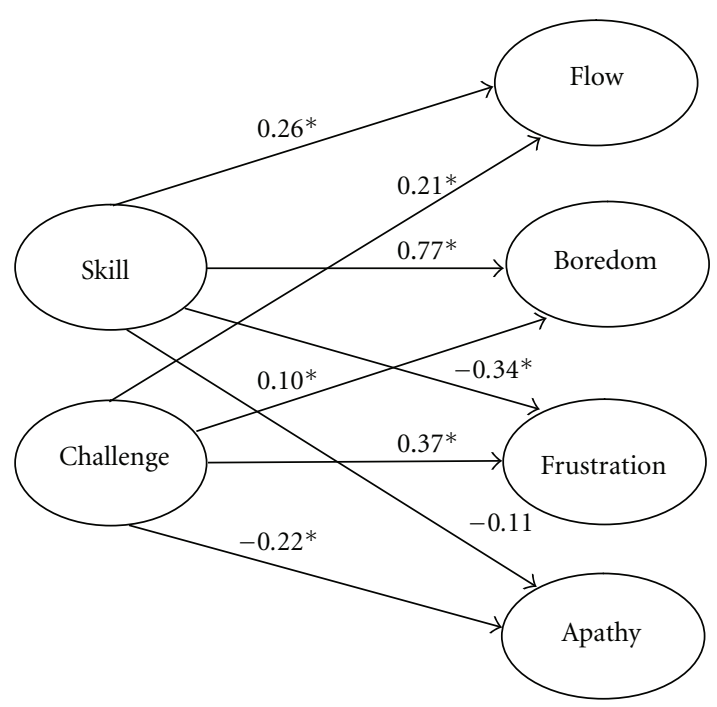

Figure 2: Results of Hypotheses Testing.

for $84.2 \%$ of gaming samples). Online game players are young adults who have few social experiences, a medium education level, and low disposable income. Restated, the time and the main purpose for the sample of the subjects to surf the Internet are to visit online gaming with high entertainment, followed by other secondary internet behaviors such as accessing email, using websites and learning online.

This study further elucidated the mechanism for formulating the four channels. Skill and challenge may either contribute individually to the formulation of the four channels or contribute interactively to their formulation, subsequently raising the issue of how skill and challenge affect the four channels. This study therefore performed an analysis of variance (ANOVA) to clarify the interacting effects of skill and challenge on the four channels. Median split method was also used to separate the sample into high-skill and low-skill groups and high-challenge and low-challenge ones. Skill (high versus low) and challenge (high versus low) were used as independent factors, while flow, boredom, frustration, and apathy were used as dependent factors.

Analytical results revealed no significant interaction between the effects of skill and challenge on the four channels $(F(1,249)<1.29, P>.26)$. This phenomenon indicated that skill and challenge contributed to the four channels independently rather than interactively. The observation that skill and challenge impacted the four channels independently justified using structural equation modeling with direct paths from skill and challenge to each of the four channels.

4.1. Hypotheses Testing. The structural equation modeling method was adopted to examine whether skill and challenge determine the four channels of flow, as predicted by the FCF theory developed by Csikszentmihalyi [5].

Figure 2 summarizes the analytical results, which supported all propositions of the FCF theory with some interesting exceptions. First, skill was positively related to flow (path coefficient $=.26, P<.05$ ), which supported $\mathrm{H} 1 \mathrm{a}$. Skill was positively related to boredom (path coefficient $=$ .77, $P<.05$ ), which supported H1b. Skill was negatively related to frustration (path coefficient $=-.34, P<.05$ ), which supported H1c. However, skill was insignificantly related to apathy ( ath coefficient $=-.11, P>.05$ ), which did not support H1d. This phenomenon may be owing to that low-skill users may still enjoy substantial achievements, which offset their feelings of apathy.

Moreover, challenge was positively related to flow (path coefficient $=.21, P<.05$ ), which supported H2a. Challenge was positively related to boredom (path coefficient $=.10$, $P<.05$ ), which was statistically significant (confidently nonrandom), yet was contrary to $\mathrm{H} 2 \mathrm{~b}$. This unexpected finding may be owing to that difficult challenges may not always be novel ones. This finding can be explained by that either low or high challenges, gamers may become bored when similar patterns of challenge repeat frequently. For certain content of game design, repeatability of challenge may allow players to become accustomed to the game, possibly making it impossible for online gamers to satisfy anticipated results for both stimulating and innovative. Therefore, with a lack of stimuli contents, online gamers may perceive less fun but more boredom. Difficult yet repetitive challenges are not considered novel to users and tend to increase their feelings of boredom. This finding concerns how challenge and boredom are related rather than gamer preference. While positively related to frustration (path coefficient $=.37, P<.05$ ), which supported $\mathrm{H} 2 \mathrm{c}$, challenge was negatively related to apathy (path coefficient $=-.22, P<.05)$, which supported $\mathrm{H} 2 \mathrm{~d}$.

\section{Discussion}

5.1. Major Findings and Theoretical Implications. This study has applied the four channels of flow (FCF) theory developed by Csikszentmihalyi [5] to online gaming. Although this study supports most of the propositions of FCF theory, some interesting exceptions are identified. As expected by the FCF theory, our results indicate that skill is positively related to flow and boredom, yet negatively related to frustration. Moreover, in-game challenge is positively related to flow and frustration, yet negatively related to apathy. Interestingly, challenge is positively (rather than negatively) related to boredom, which is inconsistent with FCF theory. This study also further elucidates the formulation of the four channels. Analysis results indicate that skill and challenge determine independently (rather than interactively) the four channels. Such a finding supports current literature that skill and challenge can predict flow. 
The FCF theory posits that skill and challenge create the four channels of flow. However, except for flow, FCF research in recent decades has not elucidated these channels satisfactorily. This study therefore examines the formulation of the four channels of flow to test the validity of FCF theory. A significant and interesting exception is that challenge is positively related to boredom, thus warranting further study.

Results of this study are also compared with current flow literature. Hsu and $\mathrm{Lu}$ [2] applied the technology acceptance model (TAM) to explain acceptance of online games and the attitudes of online gamers. Hsu and $\mathrm{Lu}$ [2] found that the ease of using an online game can increase usefulness of it and create flow. Gamers who find a game too difficult to use may not perceive the usefulness of the game and may seldom experience flow. An online gamer may eventually stop playing a certain game. If challenges provide a reverse proxy for ease of use, the positive association between challenge and flow observed in this study is interesting, given the positive association between ease of use and flow reported by Hsu and $\mathrm{Lu}[2]$. Further research is thus warranted to clarify how challenge, ease of use, and flow are related.

While identifying the features of social engagement among massive multiplayer online games (MMOs), Steinkuehler and Williams [50] established a theoretical framework on informal sociability. According to their results, online games resemble the "third places," which gamers use for participating in informal social activities. Such online participation becomes more feasible to accumulate social relations of gamers. That same study demonstrated that social aspect is a major determinant for online game use. In comparison, this study demonstrates that the flow aspect (intrinsic enjoyment with total concentration) is another major determinant for online game use. Restated, this study provides an alternative view on determinants of online game use, subsequently contributing to knowledge of gamer psychology in cyberspace.

Weibel et al. [51] found that emotional involvement and absorption constitute immersion. Moreover, openness, extraversion, and neuroticism predict immersion in a computer-mediated environment. The same investigator demonstrated the usefulness of gamer psychology in explaining gaming experiences. Results of this study correspond to those of Weibel et al. [51] by investigating gamer absorption (i.e., flow in the present study). However, our results differ from those of Weibel et al. [51] in introducing how gaming variables (i.e., gaming skill and challenge) can impact gamerexperienced absorption, thus enabling game designers or providers to help gamers experience flow and, ultimately, facilitate gamers feel immersed in one computer-mediated environment (i.e., online games in the present study).

\subsection{Research Limitations and Future Research Directions.}

This study has tested the FCF theory in the context of online games. Although online games are a widely used information system, this represents a limitation of this study. Future studies may replicate the results of this study by applying FCF theory to other information systems in order to obtain further insight into the applicability of the FCF theory in other information systems.
Respondents filled out the questionnaire survey when they were available, increasing the accuracy of their memory retrieval. Previous studies have frequently adopted the approach of online survey without preceding gaming sessions [52], implying that memory bias may be acceptable in this case. However, such a design may fail to ensure that all respondents filled out the questionnaire survey immediately following their game play, thus representing another limitation of this study. We thus recommend that future studies devise an effective method to ensure that all respondents filled out the questionnaire survey immediately following their game play by using their computers at home, in a dormitory, or in an Internet café, where they are accustomed to play online games.

As flow increases the retention of online gamers, future studies may further clarify how customer loyalty and flow are related to computer user behavior. Further research should explore the potential applications of FCF theory in various disciplines such as social psychology, information management, and Internet marketing.

Hsu and $\mathrm{Lu}[2]$ suggested examining the role of personality in online gaming. Recent studies have demonstrated that personality traits are critical to achieve fulfillment and gaming behavior $[53,54]$. Future studies may also further compare the likelihood of boredom, frustration, and apathy between online gamers with different personality traits.

Moreover, results of this study are consistent with four channels of flow theory developed by Csikszentmihalyi [5]. This study supports most propositions of the theory. However, two exceptions are observed: skill is insignificantly related to apathy; in addition, challenge is positively related to boredom. Future studies should address the same issue by using different measures for skill and challenge and by studying a multinational sample. Furthermore, future studies should address how boredom, frustration, and apathy influence user psychology and the behavior of information system users.

Exactly how gamers rate their favorite games is worth noting, which is done so in this study to increase the variation in terms of skill and challenge. If gamers rate games they dislike or do not like much, they probably have low levels of skill and challenge because they are not highly motivated to accumulate skills and try various challenges. Moreover, gamers likely quit playing games they dislike early on, thus reducing the validity owing to an increased memory bias. However, this issue is another limitation of this study. Future studies should include only gamers who simultaneously play multiple games, which may overcome this limitation at the cost of reduced sample representation.

A recent study [55] has examined whether specific personality traits are related to the individual tendency to experience flow. We recommend that future studies investigate the relations between the Big Five personality traits or other typologies of personality traits, as well as the individual tendency to experience flow. Hopefully, such a direction can bridge the gap between psychological and information science studies.

The present study measures flow using a "explain and then directly measure" approach is widely used by 
the literature $[2,12,17,55]$. This approach has been adopted owing to its ability to directly measure the flow construct, rather than indirectly measure its correlates that may not equal the flow construct [17]. This approach regards flow as a unidimensional construct. However, some previous studies have regarded flow as a multidimensional constructs $[16,28]$. Future studies regarding flow as a multidimensional constructs should use other scales.

The literature has examined the issue of the FCF theory [56]. However, the literature has problems of reliability and validity in measurement (e.g., Cronbach $\alpha<.7$ ), casting doubts on the analytical results. Different from the literature, the present study has used the scale purification process to improve the measurement reliability and validity. That is, the analytical results of the present study are more dependable than those in the pertinent literature. Compared with the results in the literature [56], the present study is new in identifying the positive relation between challenge and boredom. The reason of the difference may be owing to the data reliability and validity prior to conducting analyses.

\section{Acknowledgment}

The authors thank National Science Council, Taiwan for financial support (NSC-96-2416-H-182-002-MY3).

\section{References}

[1] D. L. Hoffman and T. P. Novak, "Marketing in hypermedia computer-mediated environments: conceptual foundations," Journal of Marketing, vol. 60, no. 3, pp. 50-68, 1996.

[2] C. L. Hsu and H. P. Lu, "Why do people play on-line games? An extended TAM with social influences and flow experience," Information and Management, vol. 41, no. 7, pp. 853-868, 2004.

[3] C. Mathwick and E. Rigdon, "Play, flow, and the online search experience," Journal of Consumer Research, vol. 31, no. 2, pp. 324-332, 2004.

[4] C. I. Teng, L. S. Huang, S. P. Jeng, Y. J. Chou, and H. H. Hu, "Who are loyal customers in online games?" in Proceedings of the International Consortium for Electronic Business, pp. 312313, ICEB Press, Waikoloa, Hawaii, USA, 2008.

[5] M. Csikszentmihalyi and I. S. Csikszentmihalyi, Optimal Experience: Psychological Studies of Flow in Consciousness, Cambridge University Press, Cambridge, UK, 1988.

[6] M. Csikszentmihalyi, "Happiness and creativity: going with flow," The Futurist, vol. 31, no. 5, pp. 8-12, 1997.

[7] Merriam-Webster Online Dictionary, "Frustration and apathy," January 2011, http://www.merriam-webster.com/.

[8] G. Chanel, C. Rebetez, M. Bétrancourt, and T. Pun, "Boredom, engagement and anxiety as indicators for adaptation to difficulty in games," in Proceedings of the 12th International MindTrek Conference: Entertainment and Media in the Ubiquitous Era (MindTrek '08), pp. 13-17, ACM Press, October 2008.

[9] C. D. Fisherl, "Boredom at work: a neglected concept," Human Relations, vol. 46, no. 3, pp. 395-417, 1993.

[10] L. D. Goodstein and R. I. Lanyon, "The process of adjustment," in Adjustment, Behavior, and Personality, L. D. Goodstein and R. I. Lanyon, Eds., pp. 155-189, Addison Wesley, 1975.
[11] K. M. Gilleade and A. Dix, "Using frustration in the design of adaptive videogames," in Proceedings of theACM SIGCHI International Conference on Advances in Computer Entertainment Technology (ACE '04), pp. 228-232, ACM Press, 2004.

[12] M. L. Korzaan, "Going with the flow: predicting online purchase intentions," Journal of Computer Information Systems, vol. 43, no. 4, pp. 25-31, 2003.

[13] M. J. Sánchez-Franco, "Exploring the influence of gender on the web usage via partial least squares," Behaviour and Information Technology, vol. 25, no. 1, pp. 19-36, 2006.

[14] Y. X. Skadberg and J. R. Kimmel, “Visitors' flow experience while browsing a Web site: its measurement, contributing factors and consequences," Computers in Human Behavior, vol. 20, no. 3, pp. 403-422, 2004.

[15] E. Bridges and R. Florsheim, "Hedonic and utilitarian shopping goals: the online experience," Journal of Business Research, vol. 61, no. 4, pp. 309-314, 2008.

[16] M. O. Richard and R. Chandra, "A model of consumer web navigational behavior: conceptual development and application," Journal of Business Research, vol. 58, no. 8, pp. 10191029, 2005.

[17] T. P. Novak, D. L. Hoffman, and Y. F. Yung, "Measuring the customer experience in online environments: a structural modeling approach," Marketing Science, vol. 19, no. 1, pp. 22$42,2000$.

[18] D. L. Hoffman and T. P. Novak, "Flow online: lessons learned and future prospects," Journal of Interactive Marketing, vol. 23, no. 1, pp. 23-34, 2009.

[19] L. E. Nacke and C. A. Lindley, "Affective ludology, flow and immersion in a first-person shooter: measurement of player experience," Loading...The Journal of the Canadian Game Studies Association, vol. 3, no. 5, 2009.

[20] A. Dietrich, "Neurocognitive mechanisms underlying the experience of flow," Consciousness and Cognition, vol. 13, no. 4, pp. 746-761, 2004.

[21] D. H. Choi, J. Kim, and S. H. Kim, "ERP training with a webbased electronic learning system: the flow theory perspective," International Journal of Human Computer Studies, vol. 65, no. 3, pp. 223-243, 2007.

[22] M. Zaman, M. Anandarajan, and Q. Dai, "Experiencing flow with instant messaging and its facilitating role on creative behaviors," Computers in Human Behavior, vol. 26, no. 5, pp. 1009-1018, 2010.

[23] C. Klimmt, A. Rizzo, P. Vorderer, J. Koch, and T. Fischer, "Experimental evidence for suspense as determinant of video game enjoyment," Cyberpsychology and Behavior, vol. 12, no. 1, pp. 29-31, 2009.

[24] D. Choi and J. Kim, "Why people continue to play online games: in search of critical design factors to increase customer loyalty to online contents," Cyberpsychology and Behavior, vol. 7, no. 1, pp. 11-24, 2004.

[25] R. Weber, R. Tamborini, A. Westcott-Baker, and B. Kantor, "Theorizing flow and media enjoyment as cognitive synchronization of attentional and reward networks," Communication Theory, vol. 19, no. 4, pp. 397-422, 2009.

[26] M. Csikszentmihalyi, Beyond Boredom and Anxiety, JosseyBass, San Francisco, Calif, USA, 1975.

[27] T. P. Novak, D. L. Huffman, and A. Duhachek, "The influence of goal-directed and experiential activities on online flow experiences," Journal of Consumer Psychology, vol. 13, no. 1-2, pp. 3-16, 2003. 
[28] R. Agarwal and E. Karahanna, "Time flies when you're having fun: cognitive absorption and beliefs about information technology usage," MIS Quarterly, vol. 24, no. 4, pp. 665-694, 2000.

[29] H. Chen, R. T. Wigand, and M. S. Nilan, "Optimal experience of Web activities," Computers in Human Behavior, vol. 15, no. 5, pp. 585-608, 1999.

[30] J. Chung and F. B. Tan, "Antecedents of perceived playfulness: an exploratory study on user acceptance of general information-searching websites," Information and Management, vol. 41, no. 7, pp. 869-881, 2004.

[31] A. Rollings and E. Adams, Andrew Rollings and Ernest Adams on Game Design, New Riders, Indianapolis, Ind, USA, 2003.

[32] C. I. Teng, "Customization, immersion satisfaction, and online gamer loyalty," Computers in Human Behavior, vol. 26, no. 6, pp. 1547-1554, 2010.

[33] D. Weibel, B. Wissmath, S. Habegger, Y. Steiner, and R. Groner, "Playing online games against computer- vs. humancontrolled opponents: effects on presence, flow, and enjoyment," Computers in Human Behavior, vol. 24, no. 5, pp. 2274 2291, 2008.

[34] C. L. Hsu and H. P. Lu, "Consumer behavior in online game communities: a motivational factor perspective," Computers in Human Behavior, vol. 23, no. 3, pp. 1642-1659, 2007.

[35] D. Williams, N. Yee, and S. E. Caplan, "Who plays, how much, and why? Debunking the stereotypical gamer profile," Journal of Computer-Mediated Communication, vol. 13, no. 4, pp. 993 $1018,2008$.

[36] R. Kammann and R. Flett, "Affectometer 2: a scale to measure current level of general happiness," Australian Journal of Psychology, vol. 35, no. 2, pp. 259-265, 1983.

[37] A. Kozma and M. J. Stones, "The measurement of happiness: development of the Memorial University of Newfoundland Scale of Happiness (MUNSH)," Journals of Gerontology, vol. 35, no. 6, pp. 906-912, 1980.

[38] C. K. J. Wang, A. Khoo, W. C. Liu, and S. Divaharan, "Passion and intrinsic motivation in digital gaming," Cyberpsychology and Behavior, vol. 11, no. 1, pp. 39-45, 2008.

[39] C. I. Teng, S. S. Chang, and K. H. Hsu, "Emotional stability of nurses: impact on patient safety," Journal of Advanced Nursing, vol. 65, no. 10, pp. 2088-2096, 2009.

[40] C. I. Teng, Y. I. L. Shyu, W. K. Chiou, H. C. Fan, and S. M. Lam, "Interactive effects of nurse-experienced time pressure and burnout on patient safety: a cross-sectional survey," International Journal of Nursing Studies, vol. 47, no. 11, pp. 1442-1450, 2010.

[41] R. P. Bagozzi and Y. Yi, "On the evaluation of structural equation models," Journal of the Academy of Marketing Science, vol. 16, no. 1, pp. 74-94, 1988.

[42] J. C. Anderson and D. W. Gerbing, "Structural equation modeling in practice: a review and recommended two-step approach," Psychological Bulletin, vol. 103, no. 3, pp. 411-423, 1988.

[43] C. Fornell and D. F. Larcker, "Evaluating structural equation models with unobservable variables and measurement errors," Journal of Marketing Research, vol. 18, no. 1, pp. 39-50, 1981.

[44] M. W. Browne and R. Cudeck, "Single sample cross-validation indices for covariance structures," Multivariate Behavioral Research, vol. 24, no. 4, pp. 445-455, 1989.

[45] M. W. Browne and R. Cudeck, "Alternative ways of assessing model fit," in Testing Structural Equation Models, K. A. Bollen and J. S. Long, Eds., pp. 136-162, 1993.

[46] J. H. Steiger, "Point estimation, hypothesis testing, and interval estimation using the RMSEA: some comments and a reply to Hayduk and Glaser," Structural Equation Modeling, vol. 7, no. 2, pp. 149-162, 2000.

[47] R. P. Bagozzi, "Structural equation models are modelling tools with many ambiguities: comments acknowledging the need for caution and humility in their use," Journal of Consumer Psychology, vol. 20, no. 2, pp. 208-214, 2010.

[48] K. A. Bollen, Structural Equations with Latent Variable, John Wiley \& Sons, New York, NY, USA, 1989.

[49] P. M. Podsakoff, S. B. MacKenzie, J. Y. Lee, and N. P. Podsakoff, "Common method biases in behavioral research: a critical review of the literature and recommended remedies," Journal of Applied Psychology, vol. 88, no. 5, pp. 879-903, 2003.

[50] C. A. Steinkuehler and D. Williams, "Where everybody knows your (screen) name: online games as 'third places," Journal of Computer-Mediated Communication, vol. 11, no. 4, pp. 885909, 2006.

[51] D. Weibel, B. Wissmath, and F. W. Mast, "Immersion in mediated environments: the role of personality traits," Cyberpsychology, Behavior, and Social Networking, vol. 13, no. 3, pp. 251-256, 2010.

[52] R. T. A. Wood, M. D. Griffiths, D. Chappell, and M. N. O. Davies, "The structural characteristics of video games: a psycho-structural analysis," Cyberpsychology and Behavior, vol. 7, no. 1, pp. 1-10, 2004.

[53] C. I. Teng, "Personality differences between online game players and nonplayers in a student sample," Cyberpsychology and Behavior, vol. 11, no. 2, pp. 232-234, 2008.

[54] C. I. Teng, "Online game player personality and real-life need fulfillment," International Journal of Cyber Society and Education, vol. 2, no. 2, pp. 39-50, 2009.

[55] C. I. Teng, "Who are likely to experience flow? Impact of temperament and character on flow," Personality and Individual Differences, vol. 50, no. 6, pp. 863-868, 2011.

[56] C. I. Teng and S. H. Lin, "Examination of four channels of flow," in Proceedings of the 9th International Consortium for Electronic Business, pp. 99-102, 2009. 

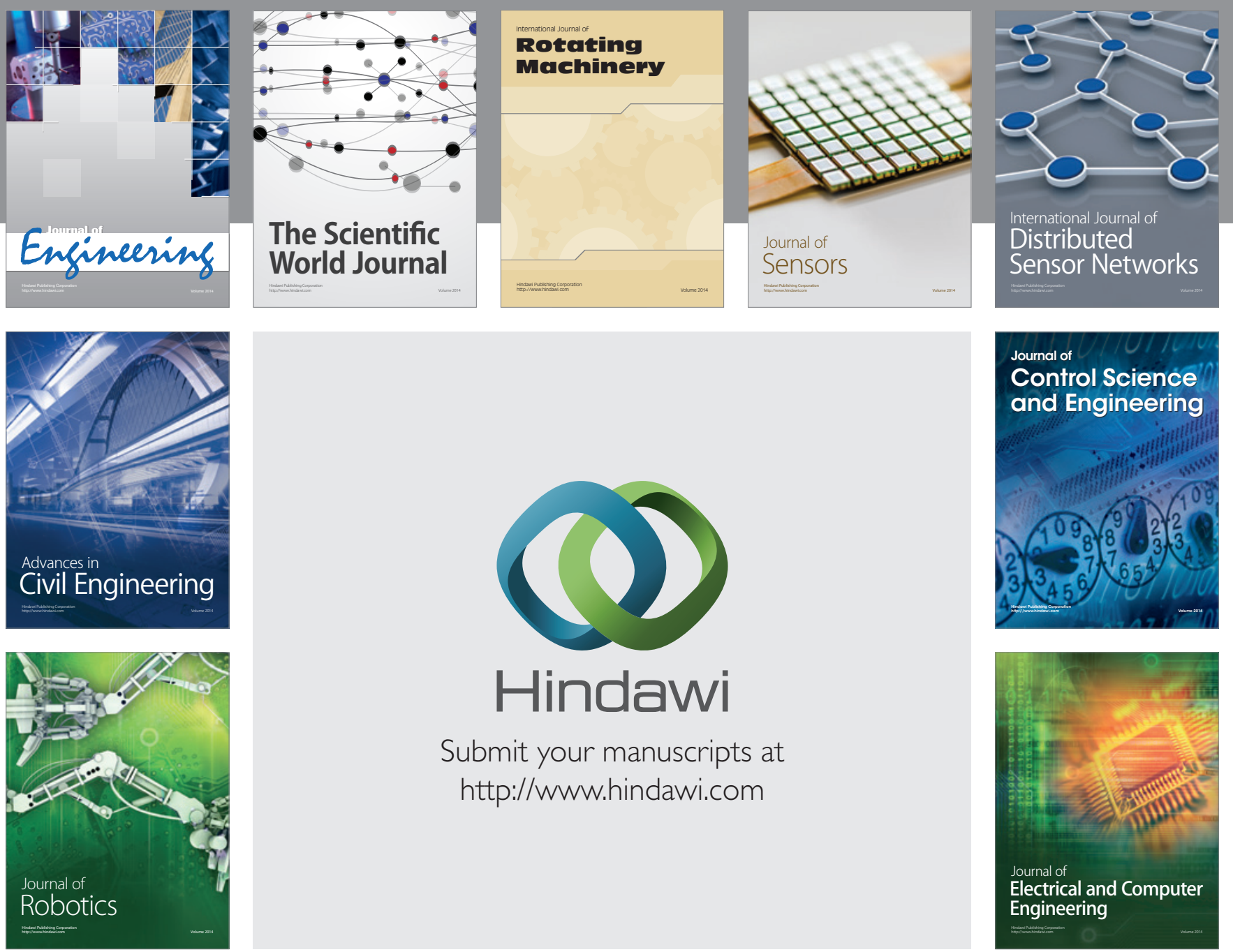

Submit your manuscripts at

http://www.hindawi.com
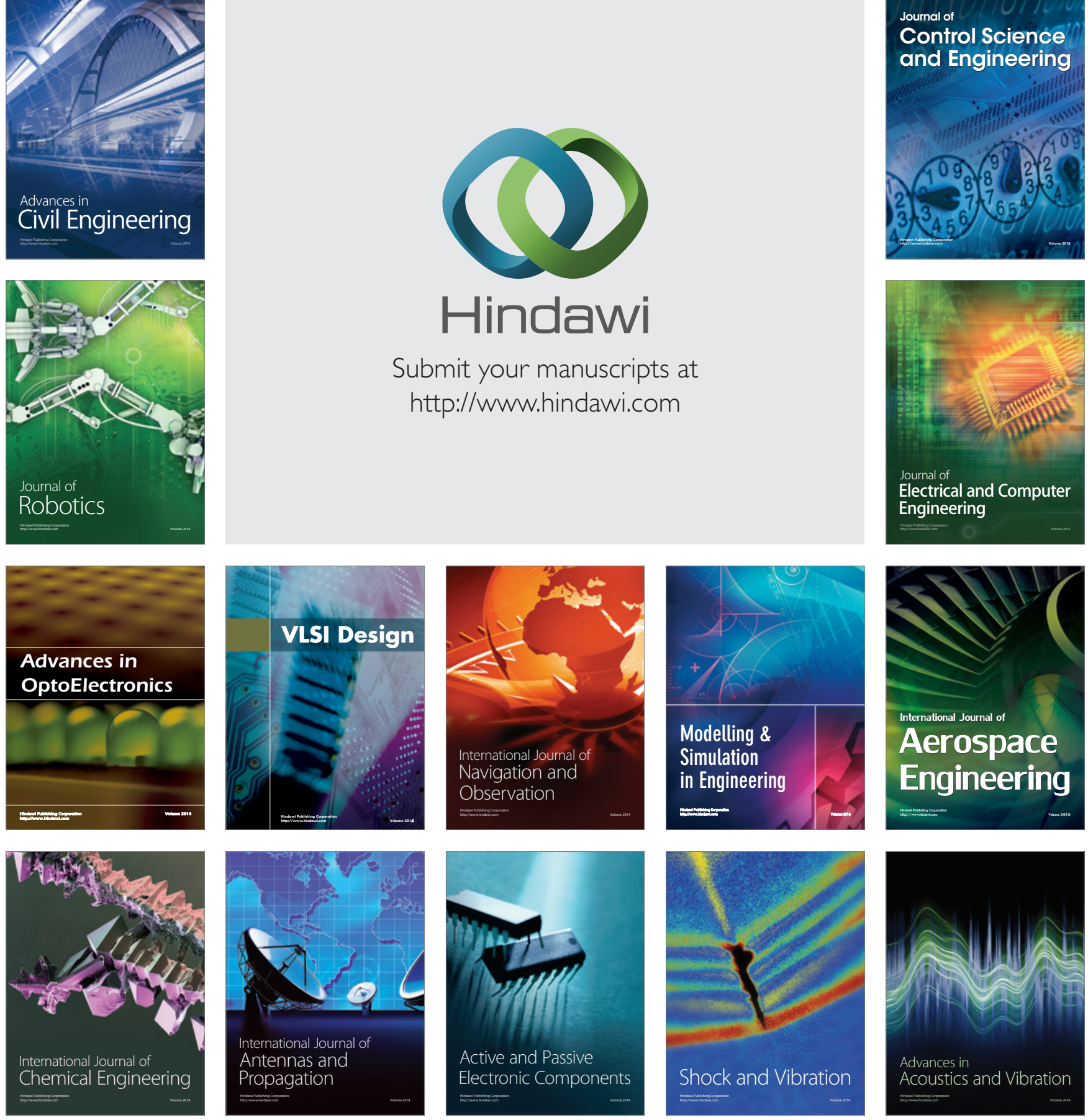